Editorial

\title{
Europe's Future Is Digital: A Broad Vision of the Industry 4.0 Concept beyond Direct Manufacturing in the Company ${ }^{\dagger}$
}

\author{
Liviu Moldovan * and Adrian Gligor (1) \\ Faculty of Engineering and Information Technology, "George Emil Palade" University of Medicine, Pharmacy, \\ Science, and Technology of Târgu Mures, 38 Gh. Marinescu Street, 540139 Târgu Mures, Romania; \\ adrian.gligor@umfst.ro \\ * Correspondence: liviu.moldovan@umfst.ro; Tel.: +40-740-498-427 \\ + Presented at the 14th International Conference on Interdisciplinarity in Engineering-INTER-ENG 2020, \\ Târgu Mures, Romania, 8-9 October 2020.
}

Published: 17 December 2020

These proceedings contain research papers that were accepted for presentation at the 14th International Conference Inter-Eng 2020 "Interdisciplinarity in Engineering", which was held on 8-9 October 2020, in the city of Târgu Mureș, Romania. It is a leading international professional and scientific forum for engineers and scientists to present research works, contributions and recent developments as well as current practices in engineering, which is falling into a tradition of important scientific events taking place at Faculty of Engineering and Information Technology in the "George Emil Palade" University of Medicine, Pharmacy Science, and Technology of Târgu Mures, Romania.

Inter-Eng marks this year seventeen years of existence, the first edition taking place in 2003. Meanwhile the conference prestige grew primarily organizational aspect of arousing the interest of national and international institutions in the country and abroad to become conference partners. Therefore, this year's edition is organized in cooperation with the Romanian Academy of Technical Sciences, McMaster University from Canada and Zagazig University from Egypt. The conference partners from Romania are Romanian General Association of Engineers in Romania, Mureș County Council and Târgu Mureș City Hall.

From another perspective, the international visibility of the conference results is an outstanding increase, the conference proceedings in the previous six editions Inter-Eng 2013, 2014, 2015, 2016, 2017, 2018 and 2019 being published as dedicated issues in Elsevier's Procedia Technology, Procedia Engineering and Procedia Manufacturing journals [1-3], that are made available in open access on Elsevier's Science Direct for researchers worldwide. These volumes are indexed in the Clarivate Analytics Conference Proceedings Citations Index.

Inter-Eng conference starts from the observation that today in full XXIst century, the era of high technology, without new approaches in research one cannot speak of a harmonious society. The theme of the conference proposing a new approach related to "Industry 4.0" the development of a new generation of smart factories grounded on the manufacturing and assembly process digitalization, is related to Advanced manufacturing technology, Lean manufacturing, Sustainable manufacturing, Additive manufacturing, Manufacturing tools and equipment.

The conference slogan in this year is "Europe's future is digital: a broad vision of the Industry 4.0 concept beyond direct manufacturing in the company".

Industry is a central pillar of the European economy, and the EU production sector represents more than 95 million jobs. Nowadays, the challenge is to ensure that all industrial sectors make the best use of new technologies and to manage their transition to higher value products and processes, commonly known as "Industry 4.0" [4]. 
Currently, manufacturing production is determined by international competition and the requirement to rapidly adapt production to market needs. But manufacturing companies are facing a huge challenge in implementing Industry 4.0 solutions. The concept of the industry is not only limited to the manufacturing system, but also comprises the supply system and the sales system of the enterprise, its entire value chain which constitutes a globalized system of links of all the enterprises including all their functions and services.

These demands can only be met through the radical advances of current manufacturing technology supported by Industry 4.0 which is integrating business and production processes, as well as integrating suppliers and customers into the company's value chain.

Through vertical networking of the smart factory's cyber physical systems, changes in stocks or demand or even faults in equipment are quickly addressed. Both production and maintenance management of the factory can be organised automatically and independently of each other. With real-time virtualisation of everything in the factory, parts and equipment can be located anywhere and the workflows are self-organised for optimum efficiency.

Horizontal integration brings the efficiency of the network to other outside organisations, such as subcontractors, suppliers, logistics service providers, distribution points and customers. As products become more integrated with the Internet of Things, through embedded electronics and communication technologies, the link with the manufacturer is maintained throughout its life cycle.

Exponential technologies represent one of the major characteristics of Industry 4.0 serving as a catalyst for improvements in the manufacturing process. These technologies are evolving and enabling change at an accelerating pace. Innovation through exponential technologies can help manufacturers develop faster, be more flexible and unlock new forms of value.

Governed by vertical and horizontal integration and enabled by cyber physical systems, as well as by the internet of things, the organisation of a factory of the future will be more flexible, changeable, decentralised, and not as deterministic as today's organisations.

Meeting these advances is different, because at present there are only a few "islands" of the Industry 4.0 concept.

Delays of manufacturing companies in adapting to the transformations produced by digitization will lead to low competitiveness, with adverse effects for their future. The better the new technologies of "Industry $4.0^{\prime \prime}$ are understood and applied in practice, the more these companies will gain a competitive advantage.

This year, the InterEng conference has distinguished keynote speakers:

- Prof.dr.habil. Laszlo Kovacs, University of Miskolc, Hungary;

- Prof.dr. Abdelazim M. Negm, University of Zagazig, Egypt;

- Prof.dr. Mo Elbestawi, McMaster University, Canada;

- Prof.dr. Ahmed Hussein Ibrahim, University of Zagazig, Egypt.

They are researchers with outstanding results in their field of activity, giving the scientific weight to the conference. On behalf of the scientific committee, we thank them for attending the Inter-Eng 2020 conference.

During this edition of the conference are listed 123 papers distributed in five sessions. It is remarkable the international participation with papers from 12 countries on five continents such as Romania, Hungary, Switzerland, Spain, Finland, Slovakia, Canada, Egypt, Morocco, Saudi Arabia, Algeria and India.

The Inter-Eng 2020 Conference submissions have been anonymously reviewed by two independent reviewers, to ensure the final standard of the accepted submissions. On behalf of the scientific committee of Inter-Eng 2020, we thank all reviewers for their hard work.

We are especially grateful to the authors who submitted their papers to this conference and to the presenters who provided the substance of the meeting. 
These Proceedings book contain a rich experience of the academic and research institutions and the industry on diverse themes related to advances and innovation in technology. We do hope that researchers, knowledge workers and innovators both in academia and industry will find it a valuable reference material.

These conference proceedings are made available with the professional support from:

Răzvan CAZACU;

Adrian-Vasile DUKA;

Lucian DULĂU;

Mircea DULĂU;

Cristian-Dragoș DUMITRU;

Stelian-Emilian OLTEAN;

Liviu POP.

The Inter-EngConference has become a tradition, and we are optimistic that it will be maintained in future, contributing to the development of emerging technologies in various fields.

Last but not least, we hope that everybody had a good time in Târgu Mureș, and we invite participants to join us for next year's edition of the Inter-Eng Conference.

\begin{tabular}{ccc}
\hline Târgu Mureș, Romania & Liviu MOLDOVAN & Adrian GLIGOR \\
\hline 11 October 2020 & President of Scientific Committee & Executive Director \\
\hline
\end{tabular}

Author Contributions: Conceptualization, L.M.; Resources, A.G.; Writing-Original Draft Preparation, L.M.; Writing-Review \& Editing, A.G. All authors have read and agreed to the published version of the manuscript.

Funding: This research received no external funding.

Acknowledgments: The authors gratefully appreciate the help of scientific committee as well as organizing committee.

Conflicts of Interest: The authors declare no conflict of interest.

\section{References}

1. Moldovan, L. State-of-the-art analysis on the knowledge and skills gaps on the topic of Industry 4.0 and the requirements for work-based learning. Procedia Manuf. 2019, 32, 294-301. [CrossRef]

2. Moldovan, L. Review of legislation framework in the field of work-based learning. Procedia Manuf. 2019, 32, 302-308. [CrossRef]

3. Moldovan, L.; Gligor, A. "Industry 4.0" the development of a new generation of smart factories grounded on the manufacturing and assembly process digitalization. Procedia Manuf. 2020, 46, 1-3.

4. International Conference Inter-Eng 2020 "Interdisciplinarity in Engineering". Available online: https: //inter-eng.umfst.ro/2020/ (accessed on 11 October 2020).

Publisher's Note: MDPI stays neutral with regard to jurisdictional claims in published maps and institutional affiliations.

(C) 2020 by the authors. Licensee MDPI, Basel, Switzerland. This article is an open access article distributed under the terms and conditions of the Creative Commons Attribution (CC BY) license (http://creativecommons.org/licenses/by/4.0/). 